\section{EFFECTS OF INLET CLOSURE LEVEL ON VIBRATION CHARACTERISTICS OF A MODIFIED CENTRIFUGAL FAN}

\author{
Zaimara*, Mursalimb, Hammada Abbasc, Supratomob
}

aDepartment Agro Industry, Agricultural Polytechnic of Pangkep State, 90655 Pangkep, South Sulawesi, Indonesia bDepartment Agricultural Engineering, Hasanuddin University, 90245 Makassar, Indonesia cDepartment Mechanical Engineering, Hasanuddin University, 92173 Gowa, Indonesia
Article history

Received

17 November 2017

Received in revised form

1 June 2018

Accepted

15 June 2018

Published online

5 October 2018

*Corresponding author zaimar@mail.polipangkep.ac.id

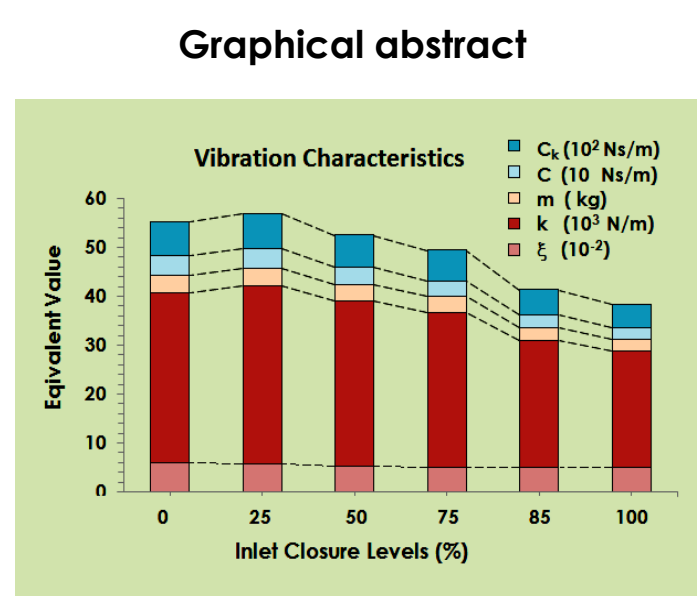

\begin{abstract}
Inlet is one of the key parameters that plays an important role in a centrifugal fan. The change of parameters in an inlet can cause static and dynamic pressures in the fan housing. As a consequence, high turbulence can produce vibration. The aim of this research is to study the inlet closure level effects on the vibration characteristics of a modified centrifugal fan. The Inlet closure levels consist of $0 ; 25 ; 50 ; 75$; $85 ; 100 \%$ that were tested to examine the vibration characteristic value $\left(\xi, m, k, C_{k}, C\right)$. The test used a randomized complete design with full factorial experiment. Data analysis employed variance and regression analysis. The results show that the inlet closure effect is significant to the value of the vibration characteristics. The increase of the inlet closure level can cause the quadratic decrease of the values of the vibration characteristics. In addition, the increase of the inlet closure level had no impact on the applied resonance frequency levels. These experimental results obtained the highest values of the vibration characteristic at the inlet closure level of $25 \%$.
\end{abstract}

Keywords: Centrifugal fan, inlet closure, high turbulence, resonance frequency, vibration characteristic

(C) 2018 Penerbit UTM Press. All rights reserved

\subsection{INTRODUCTION}

A centrifugal fan is a device that is used to move air from the inlet to the outlet sides. This movement is rotated by an impeller. Increasing velocity movement of airflow can produce kinetic energy on an impeller blade that increases dynamic pressure in the fan housing [1]. The kinetic energy can be converted to a static pressure that increases an airflow pressure. This conversion can overcome resistance factors occurring at the ducts, dampers and other factors $[2,3]$.

An impeller, in general, connects directly to the shaft of an electric motor rotates at the higher speed. This higher speed can generate a centrifugal force effect on the inside of the impeller that creates the suction channel. In addition, the impeller can produce a vacuum on the inlet suction side when the impeller rotates because of the centrifugal force. It produces both positive and negative pressures: a positive pressure is used to push air or fluid toward an outlet side and a negative pressure is used to suck fluid at the inlet side. It is interesting to note that the amount of energy delivered to fluid has to be parallel to the velocity either at the edge or the tip of the impeller vane [4].

One of the key parameters to determine a fan performance can be seen from the change in shapes, dimensions, profiles, structural components, and 
conditions either in an opened or closed impellers [4]. The design of parameters of the impeller blade can affect the efficiency and performance of centrifugal fans [5].

One of the factors that plays an important role in the centrifugal fan is the inlet. Change of parameters in the inlet, such as shapes, sizes, and dimensions (diameter and length) can affect the efficiency and losses of energy in the fan housing. Reducing the diameter of the inlet caused a static pressure decreased, while axial velocity increased. This condition increased a turbulent flow, vortex, and the transferred energy that was delivered to the impeller blades [6]. A rotating impeller allows for imbalance. This is due by an error of a design or a shaft position of the impeller. So, it can cause a machine fatigue and a cyclic vibration [7].

The cyclical vibration is the most common vibrations in rotating engine components that can cause damage to the engine. Such vibration can occur gradually and continuously. If the fan runs at a condition of the lower current, then, it can generate a peak pressure. So, it may cause instability of the rotation and vibration. The other factor that causes vibration in the fan is a high turbulence. Also, if a shedding vortex occurs due to the air blowing, then it can generate vibrations with large amplitude [8].

One of the most recognizable vibrations in the fan operation is an aerodynamic vibration. This is caused by the increase of the air flow volumetric through the fan, which can reduce the vibration significantly [8]. The fan vibration can be reduced by lowering the fan speed [9]. The vibration of the machine rotor requires a precise technology to identify vibration sources that are based on the accurate research. It is done for preventing defects and protecting the machine from technical and installation error [10]. The main sources of the fan vibration are an imbalance rotor and an aerodynamic force. The aerodynamic forces cannot be determined accurately because it requires aerodynamic studies about flow characteristic in the centrifugal fan [11].

Aerodynamic forces produced by the rotating impeller can cause turbulent flow in the centrifugal fan and blower [12]. One of the causes of the fan vibration is airflow and turbulence problems. The flow restrictions cause a high discharge pressure. It generates a turbulent flow that can increase the vibration amplitude of the fan. This condition can cause noise [13]. The centrifugal fan could be an occurrence of a high turbulence in the area between the inlet and one-third of the width of the impeller [14].

The vibration does not occur when a fan frequency is equal to a shaft frequency. This problem, if it had the different ranges of airflow, then could produce dangerous vibrations $[15,16]$. The machine vibration is a frequency component that indicates the condition of the rotating element with particular vibration characteristic [17]. The vibration characteristic include natural frequencies, modes, and damping ratios should be tested in the normal condition. Within this condition, it was easier to determine the natural frequency compared to the damping ratio [4]. Therefore, the aim of this research is to study the effect of inlet closure level on the vibration characteristics of the modified centrifugal fan.

\subsection{METHODOLOGY}

\subsection{Materials}

This research used several main tools: the modified centrifugal fan with the serrated blade impeller on the inside (Table 1) and (Figure 1). The secondary tools were an analog tachometer, digital vibration meter (model GM63A), speed control, and level meter. The fluid that used is air at the initial temperature of $28{ }^{\circ} \mathrm{C}$ and the mass density of $1.225 \mathrm{~kg} / \mathrm{m}^{3}$.

Table 1 Specification of the modified centrifugal fan

\begin{tabular}{|c|c|}
\hline Components & Specifications \\
\hline Impeller & $\begin{array}{l}\text { Radial blade type, diameter of } 0.35 \mathrm{~m} \text {, } \\
\text { and } 16 \text { blades ( } 4 \text { serrated blades) }\end{array}$ \\
\hline Inlet side & $\begin{array}{c}\text { :The shape is a cylinder, diameter of } 0.27 \\
m \text {, and a cross area of } 0.057 \mathrm{~m}^{2}\end{array}$ \\
\hline Outlet side & $\begin{array}{l}\text { : The shape is a rectangle with length of } \\
0.22 \mathrm{~m} \text {, width of } 0.21 \mathrm{~m} \text { and cross area } \\
\text { of } 0.042 \mathrm{~m}^{2}\end{array}$ \\
\hline Fan housing & : Volume of $0.097 \mathrm{~m}^{3}$ \\
\hline Motor driver & : The output power of 0.75 HP (1430 RPM) \\
\hline Transmission & : The pulley and V-belt \\
\hline
\end{tabular}

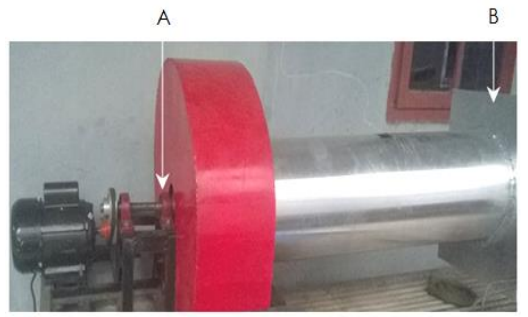

Figure 1 The modified centrifugal fan: (A) the position of the vibration meter and $(B)$ setting of the inlet closure

The position of the vibration meter is placed on the bearing point close from the impeller. It allows the effect of the vibration sources other than aerodynamic can be minimized or ignored. This was done after the right settings on the shaft of the impeller, the V-belt, and the electric motor.

\subsection{Input Parameters}

The input parameters were used to determine the element of the vibration characteristic values $(\xi, k, m, C$ and $C_{k}$ ) at the inlet closure levels $(0 ; 25 ; 50 ; 75 ; 85$; and $100 \%$ ). The input parameters were (a) mass of exciter ( $m$ 。 is $0.0048 \mathrm{~kg}$ ) and radius of exciter $\left(e_{r}\right.$ is $\left.0.01 \mathrm{~m}\right),(b)$ the rotating speeds from 400 to 1400 RPM (10 levels), (c) the influence of frequency $\left(\omega_{n}\right)$ (d) resonance frequency $\left(\omega_{r}\right)$ in $\mathrm{rad} / \mathrm{s}$, (e) an excitation force (F) in N, and (f) an amplitude of vertical direction $(\mathrm{x}$ ) in $\mathrm{mm}$. 


\subsection{Technical Analysis}

The vibration data are depicted in form of a curve of the amplitudes versus the frequencies for ordinary damped structure. For evaluation, it can use a half-power bandwidth method. The bandwidth is a difference between two frequencies (two points) with the same amplitude response. The value of the bandwidth is $1 / \sqrt{ } 2$ or 0.707 times from the resonance amplitude, while the half-power is the ratio of the frequency range between the two points to the natural frequency of the system [18].

A vibrating system comprises the dynamic variables such as an excitation force (output) that provide a response towards times (input) [19]. For analyzation, it uses a transfer function method. The transfer function is used to analyze the vibration characteristic of an object or a system experimentally. This method explains the relationship between the output of $G(f)$ and the input of $F(f)$ that provides as the transfer function $H(f)=G(f) / F(f)$ [18]. A vibration equation for one of the vibration direction is a single-degree-of-freedom system with the excitation force as follows:

$m \ddot{x}+C \dot{x}+k x=F e^{i \omega t}$

The complete solution of the equation is a homogeneous solution that represents the natural frequency and the particular solution a forced vibration of the system. It is caused by the excitation force [20]. It is based on the principle of D'Alembert's of the equation (1) and substituted into the equations (2) as follows:

$x=X e^{i \omega t} ; \dot{x}=i \omega X e^{i \omega t}$ and $\ddot{x}=\omega X e^{i \omega t}$

The explanation is that $\mathrm{x}$ as amplitude $(\mathrm{m}), \dot{x}$ as velocity amplitude (m/s), $\ddot{x}$ as acceleration amplitude $\left(\mathrm{m} / \mathrm{s}^{2}\right), \omega$ as frequency $(\mathrm{rad} / \mathrm{s})$, and $t$ as time $(\mathrm{s})$. If it occurs, the condition of a natural frequency is equal to a resonance frequency $\left(\omega_{r}=\omega_{n}\right)$ of the system, then, can be obtained an equation of the transfer function for an amplitude on the excitation force, as listed in equation (6).

The bandwidth method and the transfer function can obtain the values of frequencies, resonance, and equivalent values $\left(\xi, m, k, C_{k}\right.$, and $\left.C\right)$ of the vibrating system [18]. The equations (7), (8), and (9) can be used to determine the vibration characteristics [8], and the equations are listed below:

$$
\begin{aligned}
& \omega_{\mathrm{n}}=\frac{2 \pi \mathrm{n}}{60} \\
& \mathrm{~F}=\mathrm{m}_{\mathrm{o}} \mathrm{e}_{\mathrm{r}} \omega_{\mathrm{n}}^{2} \\
& \xi=\frac{\mathrm{f}_{2}-\mathrm{f}_{1}}{\mathrm{f}_{2}+\mathrm{f}_{1}}=\frac{1}{2}\left(\frac{\omega_{2}-\omega_{1}}{\omega_{\mathrm{r}}}\right) \\
& \mathrm{k}=\frac{1}{2 \xi\left[\frac{\mathrm{x}}{\mathrm{F}}\right]} \\
& \mathrm{m}=\frac{\mathrm{k}}{\omega_{\mathrm{r}}^{2}} \\
& \mathrm{C}_{\mathrm{k}}=2 \sqrt{(\mathrm{k} \cdot \mathrm{m})} \\
& \mathrm{C}=\xi \mathrm{C}_{\mathrm{k}}
\end{aligned}
$$

The symbols means $\omega_{n}$ as a natural frequency $(\mathrm{rad} / \mathrm{s}), \omega_{1}, \omega_{2}$ as the influence of frequency (rad/s), $\omega_{\mathrm{r}}$ as a resonance frequency ( $\mathrm{rad} / \mathrm{s})$, and $n$ as a rotating speed (RPM).Other symbols are $F$ as the excitation force $(N)$, $m_{\circ}$ as a mass of the exciter $(\mathrm{kg})$, eras radius of the exciter $(\mathrm{m})$, and $[x / F]$ as a transfer function value of the vertical direction amplitude $(\mathrm{m} / \mathrm{N})$. In addition, symbols are $\xi$ as a damping ratio, $k$ as stiffness $(\mathrm{N} / \mathrm{m}), m$ as a mass of the system (kg), $C_{k}$ as a critical damping coefficient (Ns/m), and $C$ as a damping factor coefficient (Ns/m).

\subsection{Statistical Analysis}

The independent variable has various levels of the inlet closure $(0 ; 25 ; 50 ; 75 ; 85 ; 100 \%)$. The dependent variables are a damping ratio, a stiffness of the system, a mass of the system, a critical damping coefficient, and a damping factor coefficient categorized as the vibration characteristics. In literature, [21] the test used a randomized complete design with the full factorial experiment (five times repetition). All of the data were collected separately from each dependent variable. It was analyzed by ANOVA and regression. All data were processed by SPSS.

\subsection{RESULTS AND DISCUSSION}

The results of the vertical direction amplitude on the influence of frequency known as the transfer function is illustrated as in Figure 2.

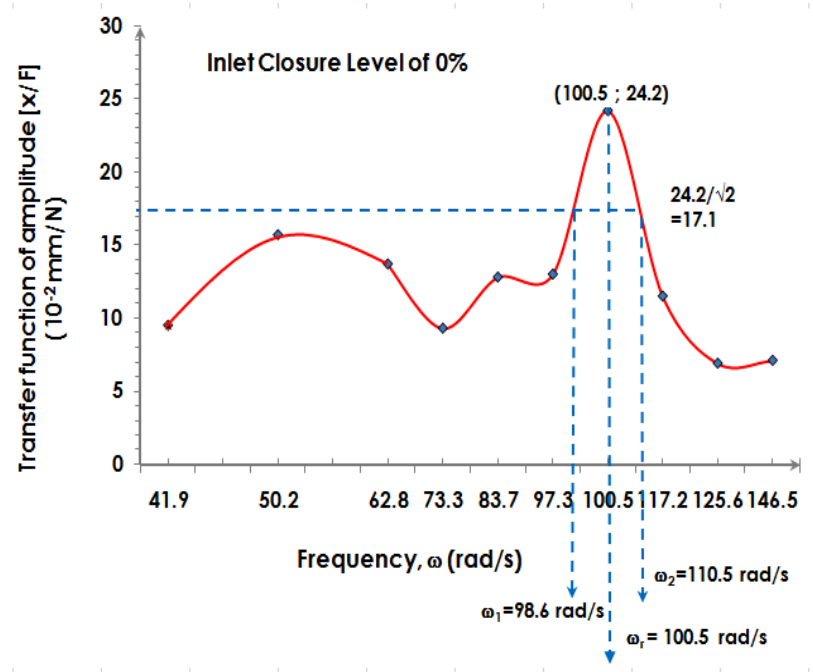

Figure 2 The transfer function of the amplitude to the influence frequency at $0 \%$ the inlet closure level

Applying bandwidth method and Equation (5) to (9) can determine the vibration characteristics of each the level of inlet closure. As an example, the calculation results at $0 \%$ the inlet closure level is presented below.

$\xi=\frac{1}{2}\left(\frac{\omega_{2}-\omega_{1}}{\omega_{r}}\right)=1 / 2(110.5-98.6) \mathrm{rad} / \mathrm{s} / 100.5 \mathrm{rad} / \mathrm{s}=0.0592$

$k=\frac{1}{2 \xi\left[\frac{x}{F}\right]}=1 /[2(0.0592)(0.000242 \mathrm{~m} / \mathrm{N})]=34898.3 \mathrm{~N} / \mathrm{m}$ 
$m=\frac{k}{\omega_{r}^{2}}=(34898.3 \mathrm{~N} / \mathrm{m}) /(100.5 \mathrm{rad} / \mathrm{s})^{2}=3.46 \mathrm{~kg}$

$C_{k}=2 \sqrt{(\mathrm{km})}=2 \sqrt{ }[(34898.3 \mathrm{~N} / \mathrm{m})(3.46 \mathrm{~kg})]=694.49 \mathrm{Ns} / \mathrm{m}^{-}$

$C=\xi C_{k}=0.0592(694.49 \mathrm{Ns} / \mathrm{m})=41.117 \mathrm{Ns} / \mathrm{m}$

By employing similar methods as above, it can also determine the vibration characteristic values with the level of the other inlet closures (Table 2).

Table 2 The input parameters of various levels of the inlet closure of a modified centrifugal fan

\begin{tabular}{cccccc}
\hline $\begin{array}{c}\text { Inlet } \\
\text { Closure } \\
\text { Level (\%) }\end{array}$ & $\begin{array}{c}\boldsymbol{\omega}_{1} \\
(\mathrm{rad} / \mathrm{s})\end{array}$ & $\begin{array}{c}\boldsymbol{\omega}_{2} \\
(\mathrm{rad} / \mathbf{s})\end{array}$ & $\begin{array}{c}\boldsymbol{\omega}_{\mathrm{r}} \\
(\mathrm{rad} / \mathbf{s})\end{array}$ & $\xi$ & $\begin{array}{c}{[\mathbf{x} / \mathbf{F}]} \\
(\mathbf{m} / \mathbf{N})\end{array}$ \\
\hline 0 & 98.6 & 110.5 & 100.5 & 0.059 & 0.000242 \\
25 & 97.9 & 109.1 & 100.5 & 0.055 & 0.000246 \\
50 & 98.6 & 109.2 & 100.5 & 0.052 & 0.000281 \\
75 & 98.6 & 108.9 & 100.5 & 0.051 & 0.000308 \\
85 & 98.9 & 109.1 & 100.5 & 0.050 & 0.000380 \\
100 & 98.9 & 108.9 & 100.5 & 0.049 & 0.000421 \\
\hline
\end{tabular}

In Table 2, it indicates that the inlet closure levels had no effect toward the resonance frequency $\left(\omega_{r}\right)$. Its value remains $100.5 \mathrm{rad} / \mathrm{s}$ because the centrifugal fan worked at same frequency (41.9 to $146.5 \mathrm{rad} / \mathrm{s})$ for all the levels. In this condition too, the values of the transfer function increased while the damping ratio decreased. Researchers [8, 20] indicated that a resonance frequency occurs when it collides with a natural frequency. At resonance frequency, few sources of vibration energy can cause large amplitude responses because that energy was stored and added concurrently.

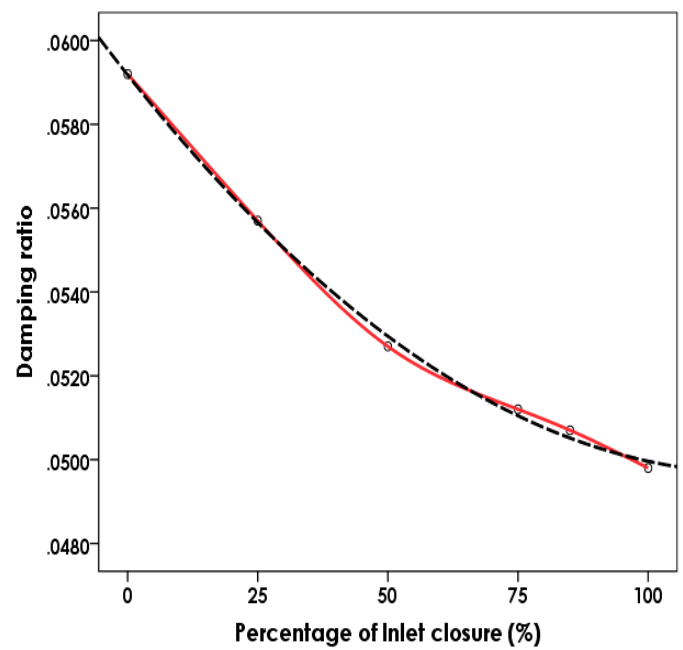

Figure 3 The result of damping ratio of the system

Both Table 2 and Figure 3 indicate that the damping ratio from 0.049 to 0.059 was classified as under damping. The value parameters were vary including over-damped system $(\xi>1)$, critical damped system $(\xi=1)$, and under-damped system $(\xi<1)$. The underdamped system occurs due to some energy in the system was dissipated, and the oscillations went down slowly to zero $[9,19]$.

With this system, the increase of the inlet closure percentage causes the damping ratio decreased. The value of the damping ratio in this test wasa slightly curved. This means that the vibrating system produce the fewer excitation forces during each of the vibration cycle. This was due to energy losses during vibration. Damping ratio was influenced by volumetric rate and air density properties that can be used as a vibration damper [22]. The inlet closure level of $0 \%$ was reached the higher damping ratio is 0.059 . This was caused by the volumetric rate and the air density in the fan housing increased when compared to the other inlet closure levels.

Researchers that investigated [23] the performance testing results of the modified centrifugal fan as an example at 800 RPM impeller speed $(83.7 \mathrm{rad} / \mathrm{s})$ showed that the decrease of the inlet closure level cause increasing air volumetric rate from $0 \mathrm{~m}^{3} / \mathrm{s}(100 \%$ inlet closure level), $0.127 \mathrm{~m}^{3} / \mathrm{s}$ (85\%), $0.19 \mathrm{~m}^{3} / \mathrm{s}$ (75\%), 0.267 $\mathrm{m}^{3} / \mathrm{s}(50 \%), 0.27 \mathrm{~m}^{3} / \mathrm{s}(25 \%)$ till it reached the higher of $0.309 \mathrm{~m}^{3} / \mathrm{s}(0 \%$ inlet closure level). The reduction of the inlet closure level also causes energy of airflow increased.

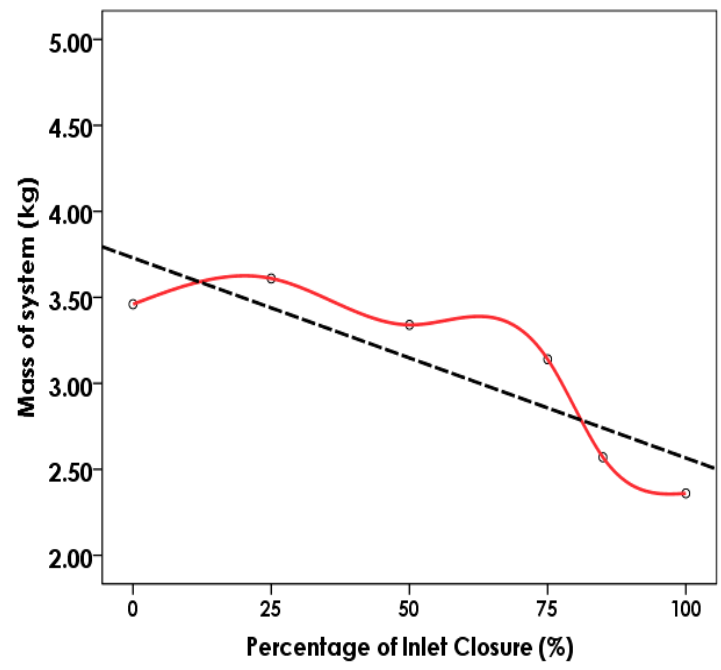

Figure 4 The result of mass of the system

The increase of the percentage of the inlet closure causes the mass of the system decreased linearly. At the inlet closure level of $25 \%$, it produced the higher mass of the system is $3.61 \mathrm{~kg}$. This happens because the increase of the volumetric rate and airflow energy in the fan. The mass of the system is presented in Figure 4. Researcher [24] applied different pressures can cause fluctuation pressure in the inlet. This can stimulate the vibration of the inlet channel system. On the other hand, the decrease of the inlet closure percentage can cause a low static pressure and a high dynamic pressure in the fan housing. This can affect the stability of the rotating impeller and increasing stiffness of mass system.

The higher stiffness of $25 \%$ the inlet closure level was $36506.2 \mathrm{~N} / \mathrm{m}$ (see Figure 5). The increase of the damping 
ratio and the mass system were concurrent with the improvement of the stiffness. Scholar [11] indicates that the machine rotation causes changes in stiffness and damping of the system.

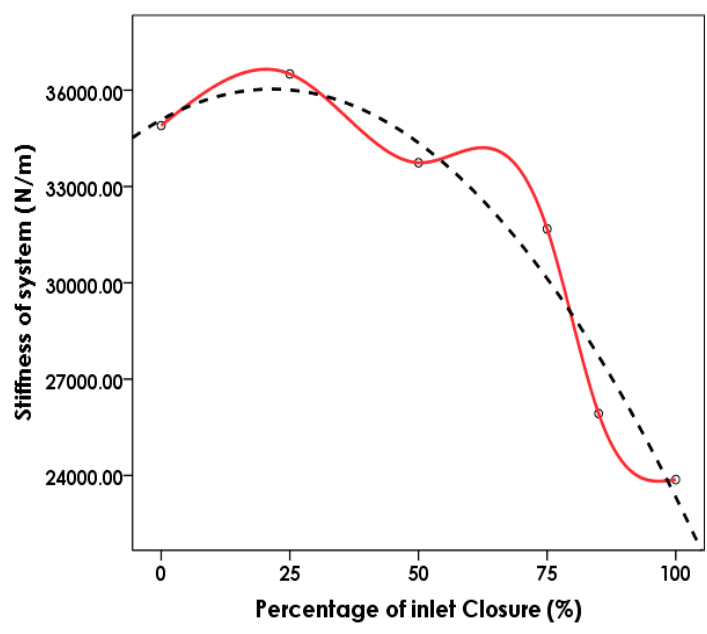

Figure 5 The result of stiffness of the system

The surge of the inlet closure percentage had little impact on the damping coefficient marked by a curve of $17.472 \mathrm{Ns} / \mathrm{m}$. The increase of the inlet closure level causes volumetric rate and air density in the fan housing decreased. Therefore, it reduces the value of damping factor coefficient (see Figure 6). In literature, [25] properties of air such as volumetric, density, and temperature can inhibit the system. Theoretically, the un-damped system can reach an infinite value. However, this condition cannot occur experimentally because each vibrating system had a damping factor that can decrease the amplitude value.

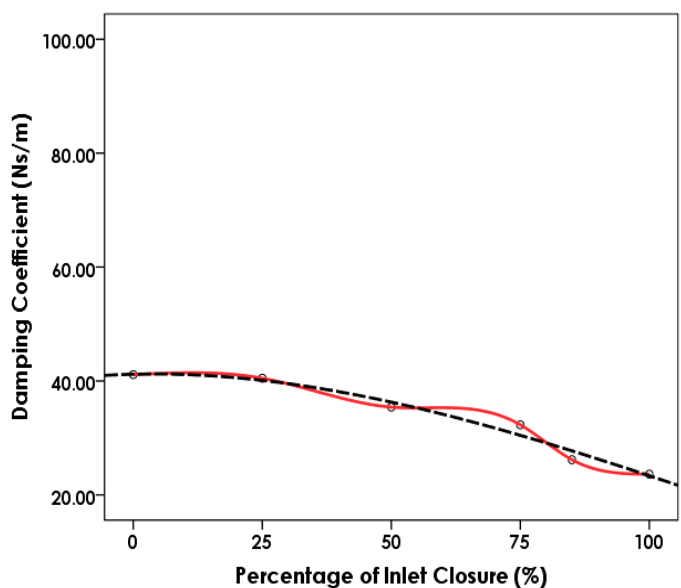

Figure 6 The result of damping factor coefficient of the system

A critical damping coefficient is the minimum quantity of a damping value. It occurs between the over and under-damped systems. A system returns to equilibrium when the amount of time is minimized. In Figure 7, it shows that the addition of the inlet closure percentage can decrease the critical damping coefficient of 151.4 Ns/m. It is influenced by the stiffness, mass system, and the natural frequency of the vibrating system. A damped system reduces the movement and fluctuation [8]. The increase of the airflow reached by opening dampers, cleaning filters and coils, testing, and by removing a section of a fan channel. These actions can reduce pressure and increase airflow of the system [7]. The incidence of vibrations can also be caused by unnecessary thing such as the unopened of the inlet control of the fan blade [26]. The cross flow of the inlet generated negative aerodynamic especially increasing load of the impeller blade and vibration [27].

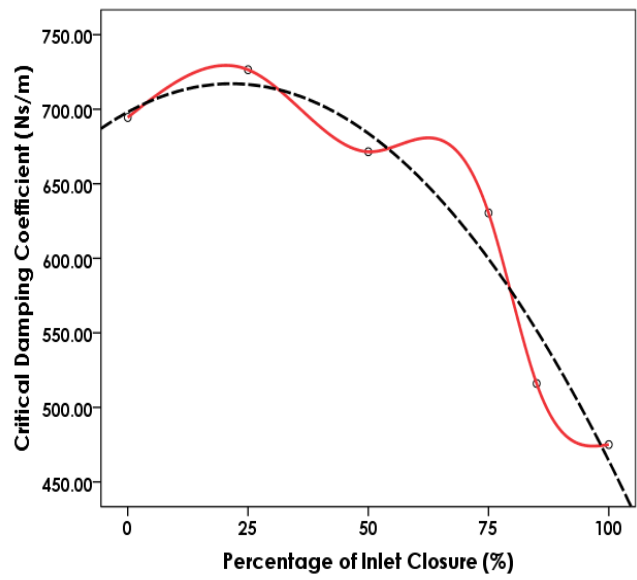

Figure $\mathbf{7}$ The result of critical damping coefficient of the system

Table 3 The results of variance and regression analysis of the vibration characteristic for the modified centrifugal fan

\begin{tabular}{cccc}
\hline $\begin{array}{c}\text { Vibration } \\
\begin{array}{c}\text { Charac- } \\
\text { teristic }\end{array}\end{array}$ & Fratio (Sig.) & $\mathbf{R}^{2}$ & Regression Equations \\
\hline$\xi$ & $658.88(0.000)$ & 0.998 & $\xi=0.059+6.5 E-07 X^{2}$ \\
$\mathrm{k}$ & $28.212(0.011)$ & 0.950 & $\mathrm{k}=35079.1+88.8 X-2.06 X^{2}$ \\
$\mathrm{~m}$ & $13.415(0.022)$ & 0.770 & $m=3.728-0.012 X$ \\
$\mathrm{C}$ & $54.278(0.004)$ & 0.973 & $\mathrm{C}=41.351-0.22 X-0.002 X^{2}$ \\
$\mathrm{C}_{\mathrm{k}}$ & $28.231(0.011)$ & 0.950 & $\mathrm{C}_{k}=698.08+1.77 X-0.041 X^{2}$ \\
\hline
\end{tabular}

Note: $R^{2}$ Value is determination index, $X$ value is a percentage of the inlet closure, and sig is significant.

The analysis of variance and regression is illustrated in Table 3. The result of regression analysis indicates that there was a quadratic decrease of the vibration characteristic values in the surge of the inlet closure percentage. It is obtained the coefficient values of $X$ or the gradient is negative. The analysis of determination coefficient $\left(R^{2}\right)$ indicated that the damping ratio had higher $\mathrm{R}^{2}$ value of $99.8 \%$. It means the effect was only $0.2 \%$ and the significant value of higher is 0.000 when it is compared with the third other factors. The result of the variance analysis indicates that the effect of the inlet closure percentage was significant to vibration characteristic system (see Table 3). 


\subsection{CONCLUSION}

The result of the variance analysis indicates that the effect of the inlet closure level is significant to value of the vibration characteristic of the system. The increase of the inlet closure levels caused quadratic decrease of the value of the vibration characteristic. In addition, the addition of the inlet closure level had no impact on the applied level of resonance frequency.

The experimental results, with the inlet closure level of $25 \%$, obtained the highest values of the damping ratio $(\xi)$ is 0.0592 , the stiffness $(k)$ is $36506.2 \mathrm{~N} / \mathrm{m}$, the mass of the system $(\mathrm{m})$ is $3.61 \mathrm{~kg}$, the damping factor coefficient (C) is $40.481 \mathrm{Ns} / \mathrm{m}$, and the critical damping coefficient $\left(C_{k}\right)$ is $726.49 \mathrm{Ns} / \mathrm{m}$.

\section{Acknowledgement}

The authors acknowledge the support from the Department of Agro Industry in Agriculture Polytechnic of Pangkep State. We are grateful to the Graduate School of Hasanuddin University for it helping in the form of the equipment and the facilities in this research.

\section{References}

[1] Dadhich, M., Jain, S. K., Sharma, V., Sharma, S. K. and Agarwal, D. 2015. Fatigue (FEA) and Modal Analysis a Centrifugal Fan. International Journal of Recent Advances in Mechanical Engineering. 4(2): 7791

DOI: https://doi.org/10.14810/ijmech.2015.4209.

[2] Kumar, P. N. and Robinson, S. S. 2014. Design Optimization of Backward Inclined Radial Blade Impeller Using ANSYS. International Journal of Engineering Development and Research. 2(1): 404-409.

[3] Thangarasu, S., Sureshkannan, G. and Dhandapani, N. V. 2015. Design and Experimental Investigation of Forward Curved, Backward Curved and Radial Blade Impellers of Centrifugal Blower. Australian Journal of Basic and Applied Sciences. 9(1): 71-75.

[4] Oyelami, A. T., Adejuyigbe, S. B., Waheed, M. A., and Ogunkoya, A. K. 2012. Analysis of Radial-Flow Impellers of Different Configurations. The Pacific Journal of Science and Technology. 13(1): 24-33.

[5] Rusiński, E., Moczko, P., Odyjas, P. and Pietrusiak, D. 2014. Investigation of Vibrations of a Main Centrifugal Fan Used in Mine Ventilation. Archives of Civil and Mechanical Engineering. http://www.elsevier.com/locate/acme.

[6] Gholamian, M., Rao, G. K. M. and Bhramara, P. 2010. Effect of Inlet on Efficiency and Flow Pattern in Centrifugal Fan Using CFD Analysis and Experimental Validation. Journal of Recent Advances in Robotics, Aeronautical and Mechanical Engineering. 37-44.

[7] Rameshkumar, G. R., Rao, B. V. A. and Ramachandran, K. P. 2010. Condition Monitoring of Forward Curved Centrifugal Blower Using Coast Down Time Analysis. International Journal of Rotating Machinery. 2010.

DOI: http://doi.org/10.1155/2010/962804.

[8] NYB (New York Blower). 2011. Fan Balance and Vibration. Engineering Letter. The New York Blower Company, 7660 Quincy Street, Willowbrook, Illinois. Retrieved from http://www.nyb.com/pdf/Catalog/Letters/EL-13.pdf.
[9] Vierck, R. K. 1995. Analysis of Vibration. Translation by Dr. Ir. Dicky Rezaldy Munaf, MS.CE, PT. Eresco Publishing, Bandung.

[10] Mažeika, P., Grigonienè, J. and Senulis, A. 2009. Influence of Foundation Stiffness on Vibrations of Rotor Systems. ULTRAGARSAS (ULTRASOUND). 64(2): 27-31.

[11] XU, C., Amano, R. S. and Lee, E. K. 2004. Investigation of an Axial Fan-Blade Stress and Vibration Due to Aerodynamic Pressure Field and Centrifugal Effects. JSME International Journal. 47(1): 75-90. DOI: https://doi.org/10.1299/jsmeb.47.75

[12] Dileep, N., Anusha, K., Satyaprathik, C., Kartheek, B. and Ravikumar, K. 2013. Condition Monitoring of FD-FAN Using Vibration Analysis. International Journal of Emerging Technology and Advanced Engineering. 3(1): 170-185.

[13] Kesler, J. D. 2014. Centrifugal Fan Using Vibration Analysis to Detect Problems. Technical Associates of Charlotte. 1-3. http://www.technicalassociates.net.

[14] Khelladi, S., Kouidri, S., Bakir, F. and Rey, R. 2005. Flow Study in the Impeller-Diffuser Interface of a Vane Centrifugal Fan. ASME Journal of Fluid Engineering. 127: 495-502. DOI: https://doi.org/10.1115/1.1900138.

[15] Datong, Q., Yijun, M., Xiaoliang, L. and Minjian, Y. 2009 Experimental Study on the Noise Reduction of Industrial Forward-Curved Blades Centrifugal Fan. Applied Acoustics. 70: 1041-1050

DOI: https://doi.org/10.1016/j.apacoust.2009.03.002

[16] Wolfram, D. and Carolus, T. 2010. Experimental and Numerical Investigation of the Unsteady Flow Field and Fone Generation in an Isolated Centrifugal Fan Impeller. Journal of Sound and Vibration. 329: 4380-4397 DOI: https://doi.org/10.1016/j.jsv.2010.04.034

[17] Kumar, C. R. and Pujari, S. 2015. Condition Monitoring and Dynamic Balancing of a Hot Air Circulation Blower by Vibration Tools. International Journal of Engineering Sciences \& Research Technology. 5(3): 40-49.

[18] Mappaita, A. 2005. Mechanical Vibration. The Practical Book. Department of Mechanical Engineering, Hasanuddin University, Makassar, Indonesia.

[19] Karyasa, T. B. 2011. Fundamentals of Mechanical Vibration. CV. Andi Offset Publishing, Jogyakarta, Indonesia.

[20] Leso, N., Puttonen, J. and Porkka, E. 2011. The Effect of Foundation on Fan Vibration Response. Rakenteiden Mekaniikka (Journal of Structural Mechanics). 44(1): 1-20.

[21] Landau, S. and Everitt, B. S. 2004. Statistical Analyses Using SPSS. Chapman \& Hall/CRC Press LLC, New York.

[22] Jayatun, Y. A. and Subagio, 2004. Dynamic Characteristic of Air Suspension. Journal of "TEKNOSAINS", Post Graduated of UGM, Jogyakarta. 17(1): 69-85.

[23] Zaimar, Mursalim, Abbas, H. and Supratomo, 2017. Performance Testing of a Modified Centrifugal Fan with Serrated Blade Impeller. International Journal of Scientific and Technology Research. 6(10): 122-125.

[24] Pittard, M. T., Evan, R. P., Maynes, R. D. and Blotter, J. D. 2004 Experimental and Numerical Investigation of Turbulent Flow Induced Pipe Vibration in Fully Develop Flow. Review of Scientific Instruments. 75(4): 2383-2401.

[25] Arief, S. and Abbas, H. 2012. Vibration Analysis of Steel Plate of Joint Variation. Proceeding in National Seminar Yearly of Mechanical Engineering-XI, 16-17th October, 2012. Gadjah Mada University, Jogyakarta.

[26] Czmochowski, J., Moczko, P., Odyjas, P. and Pietrusiak, D. 2014. Test of Rotary Machines Vibrations in Steady and Unsteady States on the Basis of Large Diameter Centrifugal Fans. Eksploatacja Niezawodnosc-Maintenance and Reliability. 16(2): 211-216.

[27] Heinemann, T. and Becker, S. 2017. Axial Fan Blade Vibration Assessment under Inlet Cross-Flow Condition Using Laser Scanning Vibrometry. Applied Sciences. 7(862): 1-16. DOI: https://doi.org / 10.3390/app7080862. 